Article

\title{
Study on the Impact of Traffic Accidents in Key Areas of Rural Roads
}

\author{
Maosheng Li, Hui Xie * and Panpan Shu
}

\section{check for updates}

Citation: Li, M.; Xie, H.; Shu, P.

Study on the Impact of Traffic

Accidents in Key Areas of Rural

Roads. Sustainability 2021, 13, 7802.

https://doi.org/10.3390/su13147802

Academic Editors: Francisco

Javier Camacho-Torregrosa and Marc A. Rosen

Received: 24 April 2021

Accepted: 25 June 2021

Published: 13 July 2021

Publisher's Note: MDPI stays neutral with regard to jurisdictional claims in published maps and institutional affiliations.
School of Traffic and Transportation Engineering, Central South University, Changsha 410075, China; maosheng.li@csu.edu.cn (M.L.); panpanshu@csu.edu.cn (P.S.)

* Correspondence: Xhnimo@csu.edu.cn

\begin{abstract}
In recent years, the proportion of rural road fatalities in the country is gradually increasing, among which the traffic safety problems are particularly prominent in the town-rural area and the town-center area. Based on the relevant accident data in Hunan Province in recent years, the chi-square test was conducted to obtain the correlation degree between each risk factor and accident severity based on gender stratification. Then, a binary logistic model was established to obtain the significant factors that affect the accident severity in the town-rural area and the town-center area, respectively. Based on the significant factors, relevant safety improvement measures were proposed for the key areas. The results show that severe accidents were significantly related to single-vehicle factors, motorcycle factors, and intersections factors in the town-rural area. In the town-center area, severe accidents were significantly related to elderly age, single-vehicle factors, and nighttime factors. The study obtained the risk factors in key areas, which can provide a reference for the improvement of traffic safety in key areas of rural roads, to ensure the safety and sustainability of rural traffic.
\end{abstract}

Keywords: rural roads; town-rural area; town-center area; traffic accident severity; binomial logistic model

\section{Introduction}

Traffic accidents have brought a huge social and economic burden to society, and the world is also working to reduce the damage caused by accidents [1,2]. At the end of 2019 , the total mileage of rural roads in China reached 4.2 million kilometers [3]. With the gradual improvement of the rural road network, the traffic safety problem in rural areas has also become a research hotspot. According to the "Administrative Measures for Rural Road Construction" promulgated by the Ministry of Transport of the People's Republic of China in 2018, rural roads are classified into three types of roads: county roads, rural roads, and village roads [4]. China prioritizes rural revitalization policies and is committed to improving road safety at the county level to achieve sustainable traffic development $[5,6]$. This paper analyzes accidents in the county area.

China's economic system reform implemented in the late 1970s led to the integration of urban-rural relations [7]. Geographically, the boundary between urban and rural areas is gradually blurred, and the two areas are integrated and permeated with each other. In terms of spatial characteristics, population attributes, land use, and regional economy, urban and rural characteristics coexist, with prominent contradictions, complex problems, and prominent traffic safety issues. In the mid-1980s, China's planning circles and land management department first put forward the concept of an "urban-rural junction" [8]. There are many names for this region, such as urban-rural ecotone and urban-rural junction zone, but the essence is the same. The urban-rural junction is a dynamic regional entity, formed by many social, economic, cultural, and other factors [8,9]. In 2002, the State Council of China defined the urban-rural boundary area as the planned area for construction land, the state-owned land and collective-owned land mixed areas, and the planned area for agricultural land, which includes the state-owned construction land [8]. Data show that 
traffic accidents occurring at or near intersections every year account for $19.8 \%$ of the annual accidents. Among the traffic accidents at intersections, the traffic accidents at the intersection of urban-rural areas account for $53.1 \%$ [10]. The government has limited investment in transportation facilities in the urban-rural area [11], indicating that the security situation of the urban-rural junction is not optimistic. There are some problems in the town-center area, such as chaotic traffic organization, mixed traffic flow, and large transit traffic flow, so the traffic safety problem needs to be solved urgently. Therefore, in this paper, the town areas, belonging to the urban-rural junction, and the town-center area are taken as the key areas. Figure 1, adapted from Reference [9], shows a schematic diagram of an urban-rural junction. The urban fringe and the rural fringe in Figure 1 are the key areas. This paper deeply analyzes the influencing factors of traffic accidents in key areas to achieve the purpose of improving the level of traffic safety in key areas of rural roads, reducing the accident rate and ensuring rural traffic safety.

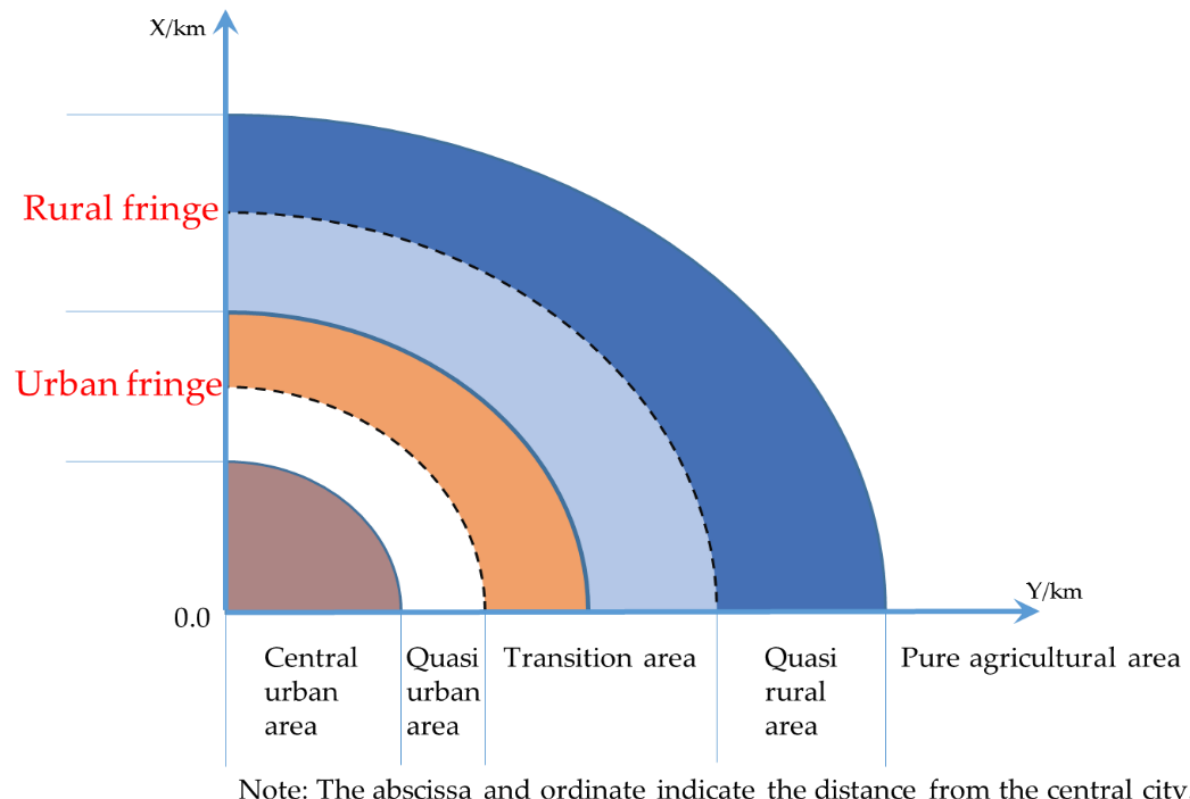

Figure 1. Schematic diagram of an urban-rural junction [9].

Previous traffic safety studies have compared and analyzed cities, suburbs, and rural areas. So far, the studies of traffic accident severity were mainly analyzed from five aspects: driver characteristics, vehicle characteristics, road characteristics, environment characteristics, and traffic management attributes [12-17]. Analyzing the mechanism of accidents requires a clear understanding of the interaction of various influencing factors [18]. Islam analyzed the severity of motorcycle accidents on rural and urban roads and found that some variables (such as motorcyclists under influence of alcohol, non-usage of the helmet, high-speed roadways, etc.) were significant in both areas [14], and Nguyen et al. discovered that perceived risks, beliefs, and environmental characteristics had a significant impact on motorcycle drivers at intersections [17]. According to data from the National Bureau of Statistics in 2019, given that the number of motorcycle traffic accidents accounted for $18.4 \%$ of the total number of traffic accidents, and the death toll from motorcycle traffic accidents was 10,474, this article analyzed the impact of motorcycles on the severity of accidents. Scholars researched drivers in urban and rural areas. Wu et al. found that significant differences existed between factors contributing to driver injury severity in single-vehicle crashes in rural and urban areas [15]. Watson et al. found that drivers in rural areas were less likely to use seat belts than in urban areas [19]. Kmet et al. analyzed the accident mortality of children and adolescents in rural and urban areas and found that the mortality rate in rural areas was five times higher than that in urban areas [20]. Singh et al. found that the main cause of most traffic accidents was the behavior of the driver, and whether the 
driver chose to reduce the speed when encountering adverse weather [21]. In terms of road characteristics research, Pokorny found that rural roads with a lane width of $1.50-2.50 \mathrm{~m}$ and a shoulder width of $0.50-0.75 \mathrm{~m}$ are safer in Norway [18]. Colonna proposed that safety principles need to be accurately followed when carrying out road geometric design [22] Calvo found that wide signs are more effective at reducing speed on weekends and when there is heavy traffic [23]. In addition to the above research, traffic safety management policies have also attracted scholars' attention [24,25]. Based on previous studies and collected accident data, this paper will research four aspects: driver characteristics, vehicle characteristics, road characteristics, and environmental characteristics.

At present, mathematical-statistical methods are widely used in the analysis of the severity of accidents. Generally, different models are adopted according to the collected data and research needs. Traditional statistical methods were used to study the field of traffic safety, such as the binary logit model [26,27], the ordered probability model (both probit and logit) [28-32], and the multinomial logit model [12,33]. The binary logit model is also widely used in various fields of sustainability to obtain the influencing factors of an event [34-37]. This paper divides the severity of accidents into severe accidents and non-severe accidents, which are binary variables, so chose to use a binary logistic model for analysis. With the advancement of urbanization in China, scholars have made some researches on the urban-rural junction because of its particularity and unique traffic characteristics. There are few studies on the comparative analysis between town-rural area and town-center area. Therefore, it is necessary to specifically explore the mechanism of accidents in different areas to provide theoretical support for improving the safety of key areas of rural roads. It is of great significance to analyze the factors of accident severity in the town-rural area and the town-center area within the county area.

This study conducted qualitative and quantitative analysis on traffic accident data in the town-rural area and town-center area in Hunan Province, and used statistical modeling methods to extract important factors affecting accidents. The factors obtained that affect the traffic accidents in key areas can provide references for the improvement of traffic safety in key areas of rural roads in the county, and also have guiding and reference significance for other rural road areas. The next section explains the source of the collected data and the theoretical basis of the analysis method. Section 3 presents the results of the model and the main influencing factors of the severity of the accident. Section 4 discusses the findings of the research. Section 5 draws conclusions and prospects.

\section{Material and Methods}

\subsection{Data Collection and Descriptive Statistical Analysis}

The traffic accident data are from the Key Laboratory of Intelligent Transportation of Hunan Province in Central South University: traffic accident data of Xiangtan County from 2010 to 2018, and traffic accident data of Hunan Province from 2014 to 2016. Python software is used to extract the accident location within the county scope and get the name of the town and village where the accident was located. A total of 67 county names are collected. All the town names, village names, and their urban-rural classification codes in 67 counties are summarized. During the study period, the urban-rural division is made according to the Provisions on Statistical Division of Urban and Rural Areas [38]. According to the urban and rural classification documents [38,39] published by the National Bureau of Statistics of China, we have summarized Tables 1 and 2. Table 1 shows the interpretation of urban-rural classification codes in the Compilation Rules for Statistical Zoning Codes and Urban-rural Division Codes [39]. The key areas are defined as the town-rural area and the town-center area. The area with the urban-rural classification code 122 is called the "town-rural area". The area with the urban-rural classification code 121 is called the "town-center area". Table 2 is the definition of the town-rural area and town-center area by the National Bureau of Statistics. 
Table 1. Interpretation of urban and rural classification code [39].

\begin{tabular}{cccccccc}
\hline Code & $\mathbf{1 1 1}$ & $\mathbf{1 1 2}$ & $\mathbf{1 2 1}$ & $\mathbf{1 2 2}$ & $\mathbf{1 2 3}$ & $\mathbf{2 1 0}$ & $\mathbf{2 2 0}$ \\
\hline $\begin{array}{c}\text { Specific } \\
\text { meaning }\end{array}$ & urban area & $\begin{array}{c}\text { urban-rural } \\
\text { area }\end{array}$ & $\begin{array}{c}\text { town-center } \\
\text { area }\end{array}$ & $\begin{array}{c}\text { town-rural } \\
\text { area }\end{array}$ & $\begin{array}{c}\text { special } \\
\text { area }\end{array}$ & $\begin{array}{c}\text { village-center } \\
\text { area }\end{array}$ & village area \\
\hline
\end{tabular}

Table 2. Nomenclature interpretation of the statistical urban and rural classification [38].

\begin{tabular}{cc}
\hline Noun & Meaning \\
\hline city area & The municipal districts and cities without districts, district and municipal government resident \\
committees, and other areas connected to it. \\
town area \\
In the county people's government residents and other towns outside the city; resident \\
town-rural area & $\begin{array}{c}\text { committees and other areas are connected to the actual construction of the government resident. } \\
\text { The village-level areas are connected to the town's public facilities and residential facilities. } \\
\text { The neighborhood committee area under the jurisdiction of the town, and other village-level } \\
\text { areas that are completely connected to the town's public facilities and residential facilities. }\end{array}$ \\
\hline
\end{tabular}

According to the classification standard of traffic accident severity in China [40] and the needs of this study, the accident severity is taken as the dependent variable and divided into two grades: non-severe accident (no injury/minor injury) and severe accident (severe injury/death). Severe accidents are considered to be those causing fatal, critical, and severe injuries, while others are considered to be non-severe accidents. The severity classification of accidents is consistent with the study of Pokorny et al. [18]. Given that human factors account for more than $85 \%$ of all accidents [41], so the analysis object of the severity of the accident in this study is the driver. In 12,888 county-level rural road accident data, after excluding unrecorded accident data such as road type, traffic control method, road grade, etc., the town-rural area collected 309 accidents ( 41 severe accidents and 268 non-severe accidents) and the town-center area collected 322 accidents ( 85 severe accidents and 237 non-severe accidents). An accident may involve two or more drivers' accident information. From the collected 309 accidents and 322 accidents, the town-rural area obtained 510 valid samples of drivers, and the town-center area obtained 201 valid samples of drivers. Combined with the collected sample information, Road Traffic Accident Information Code and Road Traffic Accident Scene Information Code, driver characteristics, vehicle characteristics, road characteristics, and environmental characteristics are taken as main explanatory variables. By using the contingency table analysis method and the stratified contingency table method based on gender stratification, the chi-square test is performed on town-rural area and town-center area, and the significance level is set to 0.05 to obtain Cramer's V coefficient and its statistical test power [42,43]. The stratified contingency table method decomposes accident data according to gender levels and studies the correlation between each explanatory variable and the severity of the accident at each level. After using the stratified contingency table method to eliminate the influence of gender factors, the correlation between each factor and the severity of the accident can be studied more accurately. Cramer's V coefficient is an indicator to measure the degree of correlation between two category variables [42]. The results of the chi-square test, Cramer's $\mathrm{V}$ coefficient, and its statistical test power are summarized in Tables 3 and 4. Table 5 shows the descriptive statistics of accident data in the two areas, respectively. The results are described as follows: 
Table 3. Results of the contingency table, Cramer's V, and statistical power.

\begin{tabular}{cccccccc}
\hline \multicolumn{3}{c}{ Town-Rural Area } & & \multicolumn{3}{c}{ Town-Center Area } \\
\hline Variable & $\chi^{2}$ & $p$-Value & Cramer $^{\prime} \mathbf{V}$ & Variable & $\chi^{2}$ & $p$-Value & Cramer $^{\prime} \mathbf{V}$ \\
\hline $\mathbf{N v}$ & 18.175 & 0.002 & $0.189^{*}$ & age & 8.724 & 0.044 & $0.208^{*}$ \\
$\mathbf{M o}$ & 20.972 & 0.000 & $0.203^{*}$ & $\mathbf{N v}$ & 29.916 & 0.000 & $0.386^{* *}$ \\
Lk & 4.773 & 0.029 & $0.097^{*}$ & $\mathbf{R a}$ & 5.043 & 0.025 & $0.158^{*}$ \\
Int & 4.871 & 0.027 & $0.098^{*}$ & $\mathbf{P e}$ & 6.603 & 0.018 & $0.181^{*}$ \\
\hline
\end{tabular}

Note: The number of "*" indicates the size of the statistical test power: “*” means correlation probability $<30 \%$, “**** means correlation probability $>80 \%$. Nv: Number of involved vehicles; Mo: Involving motorcycles; Lk: Whether normal road section; Ra: Road alignment; Int: Intersection or not; Pe: Accident period.

Table 4. The results of the stratified contingency table, Cramer's V and statistical power.

\begin{tabular}{|c|c|c|c|c|c|c|c|}
\hline & \multirow{2}{*}{ Variable } & \multicolumn{3}{|c|}{ Male } & \multicolumn{3}{|c|}{ Female } \\
\hline & & $x^{2}$ & $p$-Value & Cramer'V & $x^{2}$ & $p$-Value & Cramer'V \\
\hline \multirow{4}{*}{$\begin{array}{c}\text { Town-rural } \\
\text { area }\end{array}$} & Nv & 9.007 & 0.023 & 0.139 * & 12.914 & 0.018 & $0.542 * * *$ \\
\hline & Mo & 22.343 & 0.000 & 0.219 * & 0.076 & 1.000 & 0.042 - \\
\hline & Lk & 2.149 & 0.143 & $0.068-$ & 6.899 & 0.027 & $0.396 * *$ \\
\hline & Int & 2.149 & 0.061 & $0.085-$ & 6.899 & 0.176 & $0.239-$ \\
\hline \multirow{4}{*}{$\begin{array}{c}\text { Town-center } \\
\text { area }\end{array}$} & age & 3.281 & 0.175 & 0.135 - & 21.000 & 0.048 & $1.000 * *$ \\
\hline & $\mathbf{N v}$ & 31.695 & 0.000 & $0.420 * * *$ & 0.053 & 1.000 & $0.050-$ \\
\hline & $\mathbf{R a}$ & 3.827 & 0.050 & $0.050-$ & 1.706 & 0.381 & 0.191 - \\
\hline & $\mathrm{Pe}$ & 6.916 & 0.015 & $0.196 *$ & 0.111 & 1.000 & $0.073-$ \\
\hline
\end{tabular}

Note: "-" means no correlation. The number of "**" indicates the size of the statistical test power: "** means correlation probability $<30 \%$, "***" means correlation probability $30 \sim 80 \%$, "****" means correlation probability $>80 \%$. Nv: Number of involved vehicles; Mo: Involving motorcycles; Lk: Whether normal road section; Ra: Road alignment; Int: Intersection or not; Pe: Accident period.

Table 3 shows the statistically significant factors affecting the severity of the accident in the town-rural area and the town-center area. The remaining ten factors did not show statistical significance, so they are not shown in Table 3. In the town-rural area, the number of involved vehicles, whether the motorcycle is involved, whether normal road section, and whether the intersection is involved, are all related to the accident severity, with a relatively low probability of $29 \%$. In the town-center area, the age (23\%), the number of involved vehicles $(99 \%)$, the road alignment $(29 \%)$, and accident period $(29 \%)$, are all related to the accident severity. The severity of the accident is not strongly correlated with the driver's age, road alignment, and accident period. The number of involved vehicles is highly associated with accident severity. The above analysis shows that the factors in the two areas are different, and the number of vehicles involved has an impact on two key areas.

Table 4 shows the results of the chi-square test by using the stratified contingency table method, which only shows the significant factors. In the town-rural area, the factors not associated with accident severity in Table 3 are still not related to accident severity after gender stratification. At the male level, the number of involved vehicles, and whether the motorcycle is involved, are all related to the accident severity, with a relatively low probability of $29 \%$. At the female level, the likelihood that the number of vehicles involved and whether normal road sections are related to the accident severity is $88 \%$ and $50 \%$, respectively. Table 3 shows the factors that are significantly related to the severity of the accident before gender is not stratified. At the overall level of gender, the number of involved vehicles, whether the motorcycle is involved, whether the road section is normal, and whether at an intersection there is a low correlation with the accident severity. In the town-center area, the factors not associated with accident severity in Table 3 are still not associated with accident severity after gender stratification. At the male level, the number of involved vehicles $(96.2 \%)$ and the accident period $(26.6 \%)$ are associated with the accident severity. At the female level, only age $(60 \%)$ is associated with accident severity. It can be seen from Table 3 that at the overall level of gender, driver's age, number of vehicles involved, road alignment, and accident period are correlated with accident severity. There 
is a high correlation between the number of involved vehicles and accident severity. See Table 5.

Table 5. Accident descriptive statistics.

\begin{tabular}{|c|c|c|c|c|c|c|}
\hline \multirow{2}{*}{ Variable } & \multirow{2}{*}{ Symbol } & \multirow{2}{*}{ Classification } & \multicolumn{2}{|c|}{ Town-Rural Area (510) } & \multicolumn{2}{|c|}{ Town-Center Area (201) } \\
\hline & & & $\mathrm{NA}^{\mathrm{a}}$ & $\mathrm{SA}^{\mathrm{b}}$ & NA $^{a}$ & $\mathrm{SA}^{\mathrm{b}}$ \\
\hline \multicolumn{7}{|c|}{ Driver characteristics } \\
\hline \multirow{2}{*}{ Gender } & \multirow{2}{*}{ gender } & Female & $41(8.8 \%)$ & $3(7.1 \%)$ & $20(10.7 \%)$ & $1(7.1 \%)$ \\
\hline & & Male & $427(91.2 \%)$ & $39(92.9 \%)$ & $167(89.3 \%)$ & $13(92.9 \%)$ \\
\hline \multirow{3}{*}{ Age } & \multirow{3}{*}{ age } & Youth: 13 24 & $46(9.8 \%)$ & $3(7.1 \%)$ & $23(12.3 \%)$ & $1(7.1 \%)$ \\
\hline & & Middle-aged: 25 59 & $393(84 \%)$ & $36(85.7 \%)$ & $157(84 \%)$ & $10(71.4 \%)$ \\
\hline & & Old age: $\geq 60$ & $29(6.2 \%)$ & $3(7.1 \%)$ & $7(3.7 \%)$ & $3(21.4 \%)$ \\
\hline \multirow{2}{*}{$\begin{array}{l}\text { With or without } \\
\text { driver's licenses }\end{array}$} & \multirow{2}{*}{$\mathrm{Dl}$} & Without driver's license & $87(18.6 \%)$ & $8(19 \%)$ & $18(9.6 \%)$ & $0(0.0 \%)$ \\
\hline & & With driver's license & $381(81.4 \%)$ & $34(81 \%)$ & $169(90.4 \%)$ & $14(100 \%)$ \\
\hline \multicolumn{7}{|c|}{ Vehicle characteristics } \\
\hline \multirow{2}{*}{$\begin{array}{c}\text { Number of } \\
\text { involved vehicles }\end{array}$} & \multirow[b]{2}{*}{$\mathrm{Nv}$} & Single-vehicle & $7(1.5 \%)$ & $5(11.9 \%)$ & $8(4.3 \%)$ & $6(42.9 \%)$ \\
\hline & & Multi-vehicle & $461(98.5 \%)$ & $37(88.1 \%)$ & $179(95.7 \%)$ & $8(57.1 \%)$ \\
\hline \multirow{3}{*}{ Collision types } & \multirow{3}{*}{$\mathrm{Ct}$} & Frontal collision & $79(16.9 \%)$ & $10(23.8 \%)$ & $48(25.7 \%)$ & $4(28.6 \%)$ \\
\hline & & Side collision & $219(46.8 \%)$ & $19(45.2 \%)$ & $30(16 \%)$ & $2(14.3 \%)$ \\
\hline & & Other collision & $170(36.3 \%)$ & $13(31 \%)$ & $109(58.3 \%)$ & $8(57.1 \%)$ \\
\hline \multirow{2}{*}{$\begin{array}{l}\text { Involving } \\
\text { motorcycles }\end{array}$} & \multirow[b]{2}{*}{ Mo } & No & $272(58.1 \%)$ & $9(21.4 \%)$ & $108(57.8 \%)$ & $5(35.7 \%)$ \\
\hline & & Yes & $196(41.9 \%)$ & $33(78.6 \%)$ & $79(42.2 \%)$ & $9(64.3 \%)$ \\
\hline \multicolumn{7}{|c|}{ Road characteristics } \\
\hline \multirow{2}{*}{ Road alignment } & \multirow{2}{*}{$\mathrm{Ra}$} & Flat and Straight & $284(60.7 \%)$ & $27(64.3 \%)$ & $111(59.4 \%)$ & $4(28.6 \%)$ \\
\hline & & Others & $184(39.3 \%)$ & $15(35.7 \%)$ & $76(40.6 \%)$ & $10(71.4 \%)$ \\
\hline \multirow{2}{*}{ Intersection or not } & \multirow{2}{*}{ Int } & No & $396(84.6 \%)$ & $30(71.4 \%)$ & $179(95.7 \%)$ & $13(92.9 \%)$ \\
\hline & & Yes & $72(15.4 \%)$ & $12(28.6 \%)$ & $8(4.3 \%)$ & $1(7.1 \%)$ \\
\hline \multirow{2}{*}{$\begin{array}{l}\text { Whether normal } \\
\text { road section }\end{array}$} & \multirow{2}{*}{ Lk } & No & $81(17.3 \%)$ & $13(31 \%)$ & $8(4.3 \%)$ & $1(7.1 \%)$ \\
\hline & & Yes & $387(82.7 \%)$ & $29(69 \%)$ & $179(95.7 \%)$ & $13(92.9 \%)$ \\
\hline & & First-class road & $5(1.1 \%)$ & $1(2.4 \%)$ & $2(1.1 \%)$ & $0(0.0 \%)$ \\
\hline & & Second-class road & $88(18.8 \%)$ & $7(16.7 \%)$ & $17(9.1 \%)$ & $1(7.1 \%)$ \\
\hline Road grade & $\mathrm{Rg}$ & Third-class road & $155(33.1 \%)$ & $13(31 \%)$ & $31(16.6 \%)$ & $1(7.1 \%)$ \\
\hline koad grade & $\mathrm{kg}$ & $\begin{array}{c}\text { Fourth- } \\
\text { class/substandard road }\end{array}$ & $166(35.5 \%)$ & $14(33.3 \%)$ & $135(72.2 \%)$ & $11(78.6 \%)$ \\
\hline & & Other road & $54(11.5 \%)$ & $7(16.7 \%)$ & $2(1.1 \%)$ & $1(7.1 \%)$ \\
\hline & & $\begin{array}{l}\text { No traffic signal or road } \\
\text { sign or traffic police }\end{array}$ & $270(57.7 \%)$ & $21(50.0 \%)$ & $158(84.5 \%)$ & $12(85.7 \%)$ \\
\hline Traffic control & Tc & $\begin{array}{l}\text { Traffic signal or road sign } \\
\text { or traffic police }\end{array}$ & $198(42.3 \%)$ & $21(50.0 \%)$ & $29(15.5 \%)$ & $2(14.3 \%)$ \\
\hline & & Environment char & teristics & & & \\
\hline Accident time & week & $\begin{array}{c}\text { Weekday } \\
\text { (Monday-Friday) }\end{array}$ & $330(70.5 \%)$ & $28(66.7 \%)$ & $134(71.7 \%)$ & $8(57.1 \%)$ \\
\hline & & $\begin{array}{l}\text { Weekend (Saturday } \\
\text { and Sunday) }\end{array}$ & $138(29.5 \%)$ & $14(33.3 \%)$ & $53(28.3 \%)$ & $6(42.9 \%)$ \\
\hline Accident neriod & & Daytime (7-19 o'clock) & $405(86.5 \%)$ & $38(90.5 \%)$ & $149(79.7 \%)$ & $7(50 \%)$ \\
\hline Accraent perrod & Pe & $\begin{array}{c}\text { Nighttime (19-7 o'clock } \\
\text { the next day) }\end{array}$ & $63(13.5 \%)$ & $4(9.5 \%)$ & $38(20.3 \%)$ & $7(50 \%)$ \\
\hline & & Normal weather & $266(56.8 \%)$ & $30(71.4 \%)$ & $106(56.7 \%)$ & $10(71.4 \%)$ \\
\hline Weather & Wea & Adverse weather & $202(43.2 \%)$ & $12(28.6 \%)$ & $81(43.3 \%)$ & $4(28.6 \%)$ \\
\hline
\end{tabular}

Note: ${ }^{a}$ Non-severe accident; ${ }^{b}$ Severe accident; Abnormal road sections refer to ramps, dangerous roadside sections, road section entrances and exits, bridges, narrow roads, and other special sections. Other collision types include opposite scraping, other angle collisions, codirectional scraping, rear-end collision, etc. Normal weather refers to sunny days; Adverse weather means fog, snow, shade, rain, wind, and others. 


\subsection{Introduction to Model Theory}

The main purpose of this article is to obtain the factors that influence accident severity in the town-rural area and town-center area. In Section 2.1, through the use of the contingency table analysis method and the stratified contingency table method, the degree of correlation between each variable and the severity of the accident is initially obtained. Next, a binary logistics model was established to obtain how each factor affected the severity of the accident; the severity of the accident was taken as the dependent variable, each attribute variable was encoded and dummy variables were set for multi-categorical variables such as age, collision type, and road grade. See Table 6 for details.

Table 6. Variable code.

\begin{tabular}{|c|c|c|}
\hline Variable & Symbol & Value Assignment \\
\hline \multicolumn{3}{|c|}{ Accident level } \\
\hline Accident severity & $\begin{array}{l}\text { No/minor injuries } \\
\text { Severe injuries/death }\end{array}$ & $\begin{array}{l}\text { Non-severe Accident }=0 \\
\text { Severe Accident }=1\end{array}$ \\
\hline \multicolumn{3}{|c|}{ Driver characteristics } \\
\hline Gender & Gender & Female $=0$ male $=1$ \\
\hline Age & $\begin{array}{l}\text { Age } \\
\text { Age1 } \\
\text { Age2 }\end{array}$ & $\begin{array}{l}\text { Youth }(13 \sim 24 \text { years old })=1, \text { others }=0 \\
\text { Middle-aged }(25 \sim 59 \text { years old })=1, \text { others }=0 \\
\text { Old age }(\geq 60 \text { years old })=1, \text { others }=0\end{array}$ \\
\hline With or without driver's licenses & $\mathrm{Dl}$ & $\begin{array}{l}\text { Without driver's license }=0 \\
\text { With driver's license }=1\end{array}$ \\
\hline \multicolumn{3}{|c|}{ Vehicle characteristics } \\
\hline Number of involved vehicles & $\mathrm{Nv}$ & $\begin{array}{l}\text { Single-vehicle }=0 \\
\text { Multi-vehicle }=1\end{array}$ \\
\hline Collision type & $\begin{array}{l}\mathrm{Ct} \\
\mathrm{Ct} 1 \\
\mathrm{Ct} 2\end{array}$ & $\begin{array}{l}\text { Frontal collision }=1 \text {, other }=0 \\
\text { Side collision }=1 \text {, other }=0 \\
\text { Other collision }=1, \mathrm{Ct}=0, \mathrm{Ct} 1=0\end{array}$ \\
\hline Whether motorcycles involved & Mo & $\mathrm{No}=0, \mathrm{Yes}=1$ \\
\hline \multicolumn{3}{|c|}{ Road characteristics } \\
\hline Road alignment & $\mathrm{Ra}$ & Straight $=0$ Non-straight $=1$ \\
\hline Whether normal road section & $\mathrm{Lk}$ & $\mathrm{No}=0, \mathrm{Yes}=1$ \\
\hline Intersection or not & Int & No $=0$, Yes $=1$ \\
\hline Road grade & $\begin{array}{l}\text { Rg } \\
\text { Rg1 } \\
\text { Rg2 } \\
\text { Rg3 } \\
\text { Rg4 }\end{array}$ & $\begin{array}{c}\text { First-class road }=1, \text { other }=0 \\
\text { Second-class road }=1, \text { other }=0 \\
\text { Third-class road }=1 \text {, other }=0 \\
\text { Fourth-class } / \text { substandard road }=1 \text {, other }=0 \\
\text { Other road }=1, \text { other }=0\end{array}$ \\
\hline Traffic control mode & Tc & $\begin{array}{c}\text { No traffic signal or road sign or traffic police }=0 \\
\text { Traffic signal or road sign or traffic police }=1\end{array}$ \\
\hline \multicolumn{3}{|c|}{ Environment characteristics } \\
\hline Accident time & Week & Weekday $=0$, Weekend $=1$ \\
\hline Accident period & $\mathrm{Pe}$ & Daytime $=0$, Nighttime $=1$ \\
\hline Weather & Wea & Normal weather $=0$, Adverse weather $=1$ \\
\hline
\end{tabular}

Since the dependent variable in this study is a binary variable, a binary logistic model [44] is built for the accident severity in the town-rural area and the town-center area respectively. The independent variables, $X=\left(X_{1}, X_{2} \cdots, X_{n}\right)$, which influence the severity of the accident, are considered to be discrete variables. $\mathrm{P}\left(\mathrm{Y}_{\mathrm{i}}\right)$ represents the probability 
that the ith traffic accident sample is a severe accident, which is abbreviated as $P_{i}$ and is denoted as:

$$
\mathrm{P}_{\mathrm{i}}=\mathrm{P}\left(\mathrm{y}_{\mathrm{i}}=1 \mid \mathrm{X}_{1}, \mathrm{X}_{2} \cdots, \mathrm{X}_{\mathrm{n}}\right)
$$

The formula of the binary logistic regression model is:

$$
\log \operatorname{it}\left(P_{\mathrm{i}}\right)=\ln \left(\frac{\mathrm{P}_{\mathrm{i}}}{1-\mathrm{P}_{\mathrm{i}}}\right)=\alpha+\beta_{1} \mathrm{X}_{1 \mathrm{i}}+\beta_{2} \mathrm{X}_{2 \mathrm{i}}+\cdots+\beta_{\mathrm{n}} \mathrm{X}_{\mathrm{ni}}
$$

The $P_{i}$ and $1-P_{i}$ can be deduced by the above formula:

$$
\begin{gathered}
P_{i}=\frac{\exp \left(\alpha+\beta_{1} X_{1 i}+\beta_{2} X_{2 i}+\cdots+\beta_{n} X_{n i}\right)}{1+\left(\alpha+\beta_{1} X_{1 i}+\beta_{2} X_{2 i}+\cdots+\beta_{n} X_{n i}\right)} \\
1-P_{i}=\frac{1}{1+\left(\alpha+\beta_{1} X_{1 i}+\beta_{2} X_{2 i}+\cdots+\beta_{n} X_{n i}\right)}
\end{gathered}
$$

In the formula, $\alpha$ is the constant term (or intercept), and $\beta_{n}$ is the partial regression coefficient as $X_{n}$.

The odds ratio (OR) can help us understand $\beta_{\mathrm{n}}$. Whether OR is greater than 1 can be used to compare the probability of occurrence of events in the two situations [44,45]. $\exp \beta_{n}$ is the value of the odds ratio, which represents the multiple of the probability ratio of occurrence and non-occurrence of a certain result of an event relative to the corresponding ratio before the change for each unit change of the independent variable [45].

The multicollinearity diagnosis of variables is needed before establishing the regression model. Multicollinearity refers to the linear correlation between the independent variables. If there is a high correlation between the independent variables, it will seriously affect the fitting effect of the model. In statistical analysis, two statistics are generally provided: tolerance and variance inflation factor (referred to as VIF) to determine whether collinearity exists [45]. It is generally considered that severe multicollinearity exists when the tolerance is less than 0.1 [45]. The greater the variance inflation factor (the reciprocal of tolerance), the more serious the collinearity. To ensure the fitting effect of the model, it is generally believed that the variance inflation factor should not be greater than 5 , and the standard of the corresponding tolerance can also be relaxed to no more than 10 [45,46].

After collinearity diagnosis, in order to ensure the simplicity of the model, a stepwise regression method based on maximum likelihood estimation is used to screen variables, and finally only the variables that have a large contribution to the model and have a significant impact $(p<0.05)$ are retained [45].

\subsection{Model Evaluation}

The Hosmer-Lemeshow test (H-L test) is used in the binary logistic model to determine whether there is a significant difference between the predicted value and the observed value $[44,45]$. The larger the H-L test value, the better the goodness of fit, indicating that the information in the current data has been fully extracted. At the same time, the ROC curve is used to show the prediction effect of the model. The ROC curve is called the Receiver Operating Characteristic Curve, referred to as the ROC curve [45,47]. It is a widely used data statistical method, which was first applied to discrimination of medical diseases in 1960 by Lee Lusted $[47,48]$. The horizontal and vertical axes of the curve are the false positive rate (1-specificity) and the true positive rate (sensitivity) of the diagnostic data, respectively. The area under the curve, namely the AUC value (Area under Curve), can reflect the value of the diagnostic test and the accuracy of prediction. The higher the accuracy of model prediction, the higher the AUC value [45]. Adapted from reference [45], we summarize the meaning of the corresponding section of each AUC value and get Table 7. 
Table 7. The description of the AUC value [45].

\begin{tabular}{cc}
\hline Value & Instructions \\
AUC $<0.5$ & Not in line with the actual situation. Predictive diagnosis is worse \\
than random guessing. & Predictive diagnosis is completely worthless. \\
TUC $=0.5$ & The predictive diagnostic value is low. \\
$0.5<\mathrm{AUC}<0.7$ & $\begin{array}{c}\text { The predictive diagnostic value is moderate. } \\
\text { The predictive diagnostic value is high. }\end{array}$ \\
$0.7 \leq \mathrm{AUC}<0.9$ & Perfect prediction; the is no perfect predictive diagnosis in the \\
vast majority of cases.
\end{tabular}

\section{Results}

This section shows the results of the multicollinearity test of each independent variable and the parameter estimation results of the models of the severity of accidents in key areas of rural roads. The goodness of fit and prediction accuracy of the model are verified.

\subsection{Accident Model of the Town-Rural Area}

Table 8 shows the results of the diagnosis of multiplicity commonality. The variance inflation factor, VIF, of all variables is less than 10 and the tolerance is greater than 0.1 , which indicates that there is no serious collinearity problem between the variables. IBM SPSS Statistics 22.0 software is used to establish a binomial logistic regression model based on the stepwise regression method, and the estimation results of model parameters are shown in Table 9.

Table 8. Results of multicollinearity diagnosis.

\begin{tabular}{ccc}
\hline Variable & \multicolumn{2}{c}{ Collinearity Statistics } \\
\cline { 2 - 3 } & Tolerance & VIF \\
\hline Gender & 0.935 & 1.069 \\
Age & 0.984 & 1.017 \\
With or without a driver's license & 0.791 & 1.264 \\
Number of vehicles involved & 0.944 & 1.059 \\
Collision type & 0.948 & 1.055 \\
Whether motorcycles involved & 0.801 & 1.249 \\
Road alignment & 0.928 & 1.078 \\
Whether normal road section & 0.123 & 8.137 \\
Intersection or not & 0.124 & 8.095 \\
Road grade & 0.837 & 1.195 \\
Traffic control mode & 0.862 & 1.160 \\
Accident time & 0.961 & 1.041 \\
Accident period & 0.952 & 1.050 \\
Weather & 0.903 & 1.107 \\
\hline
\end{tabular}

Table 9. Estimation results of binary logistic model in town-rural area.

\begin{tabular}{ccccccc}
\hline $\begin{array}{c}\text { Independent } \\
\text { Variables }\end{array}$ & B & S.E. & Wald & df & Sig. & Exp (B) \\
\hline $\begin{array}{c}\text { Number of involved } \\
\quad \text { vehicles (1) }\end{array}$ & -2.969 & 0.703 & 17.839 & 1 & 0.000 & 0.051 \\
$\begin{array}{c}\text { Whether motorcycles } \\
\text { involved (1) }\end{array}$ & 1.914 & 0.433 & 19.538 & 1 & 0.000 & 6.780 \\
$\begin{array}{c}\text { Intersection or not (1) } \\
\quad \text { Constant }\end{array}$ & -0.834 & 0.383 & 4.737 & 1 & 0.030 & 2.303 \\
\hline
\end{tabular}

Note: B: Estimated value of constant term and partial regression coefficient $\beta$; S.E.: Standard error; Wald: chi-square value used to test the B; df: Degree of freedom; Sig.: Significance; $\operatorname{Exp}(\mathrm{B})$ : OR value. 
As can be seen from Table 9, the $p$-value of the number of involved vehicles, whether the motorcycle is involved, and whether at the intersection is less than 0.5 , indicates that these independent variables have a significant impact on the severity of the accident. Although whether a normal road is meaningful in a single independent variable analysis (contingency table analysis), it is not included in the model. Because the multivariate model considers the influence of each independent variable, the results are more objective, so when such contradictions occur, the statistical results of the multivariate model should prevail [45]. So the above three variables with significant effects are included in the model, and the regression equation is obtained as follows:

$$
\ln \left(\frac{\mathrm{P}_{\mathrm{i}}}{1-\mathrm{P}_{\mathrm{i}}}\right)=-0.976-2.969 \mathrm{Nv} 1+1.914 \mathrm{Mo} 1+0.834 \mathrm{Int} 1
$$

The results of the model show that: (i), The number of involved vehicles (1), that is, the OR value of multi-vehicle accidents is 0.051 , indicating that multi-vehicle accidents are only 0.051 times more likely to be serious than single-vehicle accidents. That is, singlevehicle accidents are more likely to be serious than multi-vehicle accidents. (ii), Whether motorcycles are involved (1), that is, the OR value of motorcycles involved is 6.780, indicating that motorcycles involved are 6.780 times the probability of serious accidents when motorcycles are not involved. It shows that serious accidents are more likely to occur when motorcycles are involved. (iii), Whether it is at an intersection (1), that is, the OR value at the intersection is 2.303, indicating that the intersection is 2.303 times the probability of serious accidents at a non-intersection, and indicating that accidents are more likely to be serious at intersections.

The goodness of fit test and prediction accuracy-test are carried out to verify goodness of fit of the model. Table 10 shows the results of the goodness of fit test and prediction accuracy-test. The significance p-value of the Hosmer-Lemeshow test is 0.322 greater than 0.05, indicating that the Hosmer-Lemeshow test is not significant, and the good goodness of fit is relatively good.

Table 10. Hosmer-Lemeshow test results.

\begin{tabular}{ccc}
\hline Chi-Square & df & Sig. \\
\hline 2.268 & 2 & 0.322 \\
\hline
\end{tabular}

IBM SPSS Statistics 22.0 software is used to draw the ROC curve to test the prediction accuracy of the model, as shown in Figure 2. The founders of IBM SPSS Statistics 22.0 were three graduate students from Stanford University in the United States. It is currently provided by IBM.

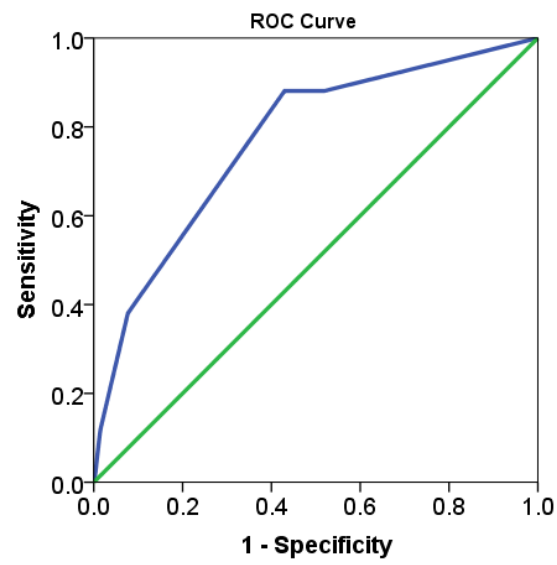

Figure 2. The ROC curve. 
Figure 2 is the ROC curve diagram of the traffic accident severity prediction model in the town-rural area. The green line in the figure is the diagonal reference line. The area under the green line segment is 0.05 , indicating that the model has no predicted value. The blue line segment is the ROC curve drawn based on the predicted value calculated by the binary logistics model. At this time, the AUC value is shown in Table 11. Among them, the outer curve, which is farther from the diagonal, has higher sensitivity and specificity than the inner curve, which is closer to the diagonal [49]. Table 11 shows the estimated value and standard error of the AUC value. The AUC value is 0.770 , and its asymptotic $95 \%$ confidence interval is (0.695 0.845). The significance $p$-value is 0.000 , which indicates that the regression model of accident severity in the town-rural area has a good prediction effect and a high predictive diagnostic value.

Table 11. The value of area under the ROC curve.

\begin{tabular}{ccccc}
\hline \multirow{2}{*}{ Area. } & \multirow{2}{*}{ Std. Error } & Asymptotic Sig. & \multicolumn{2}{c}{ Asymptotic 95\% Confidence Interval } \\
\cline { 4 - 5 } & 0.038 & 0.000 & Lower Bound & Upper Bound \\
\hline 0.770 & 0.695 & 0.845 \\
\hline
\end{tabular}

\subsection{Accident Model of the Town-Center Area}

Table 12 shows the results of the diagnosis of multiplicity commonality. Except for the variable of whether the road section is normal, the variance inflation factor of all other variables is less than 10, and the tolerance is greater than 0.1 ; therefore, in the diagnosis of collinearity, whether the road section is normal or not is excluded from the model. Table 12 shows the collinearity diagnosis results of other variables, and there is no serious collinearity problem among variables. IBM SPSS Statistics 22.0 software is used to build a binary logistic model based on the stepwise regression method, and the estimation results of model parameters are shown in Table 13.

Table 12. Multicollinearity diagnosis results table.

\begin{tabular}{ccc}
\hline Variable & \multicolumn{2}{c}{ Collinearity Statistics } \\
\cline { 2 - 3 } & Tolerance & VIF \\
Gender & 0.964 & 1.038 \\
Age & 0.985 & 1.015 \\
With or without a driver's license & 0.861 & 1.161 \\
Number of vehicles involved & 0.866 & 1.154 \\
Collision type & 0.733 & 1.364 \\
Whether motorcycles involved & 0.829 & 1.206 \\
Road alignment & 0.900 & 1.111 \\
Whether normal road section & 0.000 & - \\
Intersection or not & 0.886 & 1.129 \\
Road grade & 0.683 & 1.464 \\
Traffic control mode & 0.729 & 1.372 \\
Accident time & 0.923 & 1.084 \\
Accident period & 0.955 & 1.048 \\
Weather & 0.944 & 1.059 \\
\hline
\end{tabular}


Table 13. Estimation results of binary logistic model in town-center area.

\begin{tabular}{ccccccc}
\hline Independent Variables & B & S.E. & Wald & df & Sig. & Exp(B) \\
\hline Age & & & 10.821 & 2 & 0.004 & \\
Age (1) & -0.056 & 1.146 & 0.002 & 1 & 0.961 & 0.946 \\
Age (2) & 2.815 & 1.310 & 4.614 & 1 & 0.032 & 16.689 \\
\hline Number of vehicles & -3.230 & 0.743 & 18.891 & 1 & 0.000 & 0.040 \\
involved (1) & 1.447 & 0.664 & 4.743 & 1 & 0.029 & 4.251 \\
Accident period (1) & -0.772 & 1.221 & 0.399 & 1 & 0.528 & 0.462 \\
\hline constant &
\end{tabular}

Note: B: Estimated value of constant term and partial regression coefficient $\beta$; S.E.: Standard error; Wald: chisquare value used to test the B; df: Degree of freedom; Sig.: Significance; $\operatorname{Exp}(B)$ : OR value.

As can be seen from Table 13, the overall p-values of age, number of vehicles involved, and accident period are all less than 0.5, indicating that these independent variables have a significant impact on the severity of traffic accidents. Although the road alignment is significant in the single independent variable analysis, it is eliminated in the stepwise regression screening process in order to maximize the likelihood of the model. Therefore, the above three variables with significant effects are included in the model, and the regression equation is obtained as follows:

$$
\ln \left(\frac{\mathrm{P}_{\mathrm{i}}}{1-\mathrm{P}_{\mathrm{i}}}\right)=-0.772-0.056 \mathrm{age} 1+2.815 \mathrm{age} 2-3.230 \mathrm{Nv} 1+1.447 \mathrm{Pe} 1
$$

The interpretation of the model is as follows: (i), Age (2), that is, the OR value of the elderly is 16.689 , and it has a significant impact, indicating that the probability of serious accidents in the elderly is 16.689 times that of people in the young stage. That is, older people are more likely to have serious accidents than younger people. Age (1), that is, middle age had no significant effect ( $p$-value $0.961>0.05$ ). Considering the principle that age is a dummy variable, Age (1) is also included in the model. (ii), The number of involved vehicles (1), that is, the OR value of the multi-vehicle accident is 0.040 , and it has a significant impact, indicating that the occurrence of a multi-vehicle accident is 0.040 times the probability of a single-vehicle accident occurring as a serious accident. It shows that single-vehicle accidents are more likely to be severe. (iii), In the accident period (1), the OR value at night is 4.251 , and it has a significant impact. It shows that the probability of serious accidents at night is 4.251 times that of the day, and it shows that nighttime accidents are more likely to be severe than during the daytime.

The goodness of fit test and prediction accuracy-test are carried out to verify the goodness of fit of the model. Table 14 shows the results of the goodness of fit test and prediction accuracy test. The significance $p$-value of the Hosmer-Lemeshow test is 0.663 greater than 0.05 , indicating that the Hosmer-Lemeshow test is not significant, that is, the good goodness of fit is relatively good.

Table 14. Hosmer-Lemeshow test results.

\begin{tabular}{ccc}
\hline Chi-Square & df & Sig. \\
\hline 0.822 & 2 & 0.663 \\
\hline
\end{tabular}

IBM SPSS Statistics 22.0 software is used to draw the ROC curve to test the prediction accuracy of the model, as shown in Figure 3. 


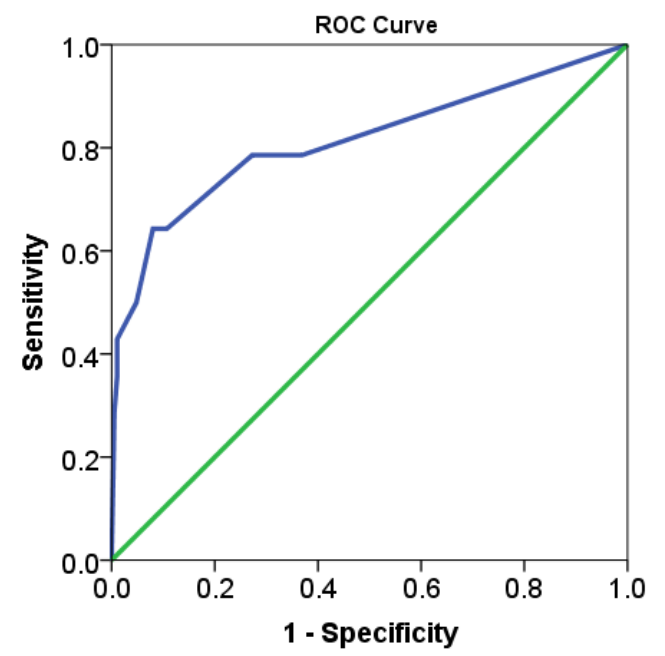

Figure 3. The ROC curve.

Figure 3 is the ROC curve diagram of the traffic accident severity prediction model in the town-center area. The meaning of the green line segment and the blue line segment in Figure 3 is the same as in Figure 2. Table 15 shows the estimated value and standard error of the AUC value. The AUC value is 0.813 , and its asymptotic $95 \%$ confidence interval is (0.664 0.961). The significance $p$-value is 0.000 , which indicates that the regression model of accident severity in the town-center area has a good prediction effect and a high predictive diagnostic value.

Table 15. The area under the ROC curve.

\begin{tabular}{ccccc}
\hline \multirow{2}{*}{ Area } & Std. Error & Asymptotic Sig. & \multicolumn{2}{c}{ Asymptotic 95\% Confidence Interval } \\
\cline { 4 - 5 } & 0.076 & 0.000 & Lower Bound & Upper Bound \\
\hline 0.813 & & & 0.664 & 0.961 \\
\hline
\end{tabular}

\section{Discussions}

\subsection{Comparative Analysis of Models}

By establishing the model of the accident severity in the above two key areas, it is concluded that the factors that affect the severity of accidents in key areas are different, and there are also the same factors. The difference in influencing factors may be at least partly attributed to the different perception, cognition and response requirements of rural and urban drivers [12]. In the town-rural area and town-center area, a valuable finding is that the number of involved vehicles has a significant impact on the severity of the accident, and both show that single-vehicle accidents are prone to be more serious than multivehicle accidents, which supported the previous findings [15]. Single-vehicle accidents are mostly collisions with guardrails, curbs, trees, etc. The guardrail can act as a buffer during the collision, which is better than other collision objects. It may be that only one driver and occupant directly participated in the accident process in a single-vehicle accident. Once a single-vehicle accident occurs, the person may be entangled in a coma, and if the traffic volume around the accident is low, it is not easy to find the injured person and the best rescue time may be missed, so the severity of the accident is usually higher. Accidents involving motorcycles in the town-rural area are prone to be more serious, because motorcycles expose drivers and passengers directly to the road environment, making them vulnerable road users. At present, the fatal factor in motorcycle accidents is mostly head injury, which is closely related to the low rate of motorcycle helmet wearing on roads in rural areas [50]. Therefore, when an accident occurs, motorcycle drivers who are not wearing helmets are often injured more seriously. 
The probability of serious accidents at intersections is higher in the town-rural area, which confirms the previous findings [14]. At the intersection, the connection between the roads of various levels in the town-rural area is not smooth enough, and the roadside obstacles are also complicated. Mixed with pedestrian traffic, the road environment is more complex, and it tests the driver's ability to operate. In addition, road users in the junction area are not sufficiently aware of safety. For example, rural drivers are more likely to have unfavorable attitudes and beliefs about seat belts than urban drivers, and these unfavorable attitudes and beliefs indicate that seat belt usage will decrease [19]. In the town-center area, the elderly are more likely to have serious accidents, which was not consistent with the studies [21,51,52], but was consistent with findings in previous studies that senior drivers are found to have a higher probability to be more severely injured in rural roads [15]. Because the reaction ability of elderly drivers is relatively slow, their physical functions are not as good as those of young and middle-aged drivers, and their body's recovery capacity after an accident is not as good as that of other age groups, serious accidents are more likely to occur. Among the three environmental factors in this paper, accident period is a significant factor in the town-center area as shown in previous research [14,21]. It is also more likely to have serious accidents at nighttime, which supports the previous finding [14]. At night, there are fewer vehicles on the road than during the day, and the driver's driving speed will be faster. At the same time, due to fatigue, weak light and other reasons, the reaction ability will be slower than during the day. The ability to deal with unexpected situations in the traffic environment is reduced. It is easy to make wrong traffic avoidance decisions.

\subsection{Suggestions for Safety Improvement}

Based on the significant factors of the two areas obtained in Section 3, combined with the " $4 \mathrm{E}$ " strategy (engineering, law enforcement, rescue, education) derived from the comprehensive practice of transportation experts, corresponding improvement suggestions are put forward. Table 16 shows safety improvement measures. Driving errors and traffic violations are major causes in $74 \%$ of the road crashes [21]. Therefore, it is particularly important to strengthen the management and training of drivers. Previous studies have shown that not using helmets has an impact on the severity of accidents [14]. Motorcycle drivers who wear helmets have a 33\% lower rate of serious accidents than those who do not wear helmets [50]. In town-rural area, it is necessary to focus on implementing the helmet-wearing policy, increase the promotion of helmet-wearing safety protection for drivers, and increase the wearing rate of motorcycle helmets. At night, visibility will be reduced, and the glare from the oncoming vehicle will distract the driver and lead to weakened responsiveness. Therefore, continuous lights should be set in the town-center area to avoid the driver suddenly entering the area of strong light or weak light and causing the wrong vision. In order to effectively reduce the severity of single-vehicle accidents, it is necessary to improve road facilities, such as roadside collision avoidance facilities.

Based on Section 2, it can be concluded that in the town-rural area, at the male level, the accident severity is related to the number of involved vehicles and whether the motorcycle is involved. Combined with the factors obtained from the model, in addition to the measures in the table, it is necessary to further strengthen the safety education and management for male motorcycle drivers. The possibility of fatal injuries from motorcycles on unlit roads was greater [14]. Therefore, during safety training, special reminders must be paid to be vigilant at night. At the female level, the accident severity is related to the number of involved vehicles, so the safety management of female drivers needs to be strengthened. In Section 2, it is concluded that at the female level in the town-center area, the accident severity is closely related to age, so it is necessary to further strengthen the special safety education and training for the elderly female drivers. At the male level, the severity of the accident is related to the number of vehicles involved and the period of the accident. Safety education can be carried out for all members of the family and other members can tell male drivers to pay attention to driving safety at night. 
Table 16. Traffic safety improvement measures.

\begin{tabular}{|c|c|c|}
\hline Key Areas & Factors & Specific Measures \\
\hline \multirow{3}{*}{ Town-rural area } & Single-vehicle accident & $\begin{array}{l}\text { Improve road facilities such as roadside collision avoidance facilities. } \\
\text { Improve the road monitoring system to prevent individuals from being unable to help } \\
\text { themselves when single-vehicle accidents occur in areas with low traffic volume. } \\
\text { Improve the accident rescue system. }\end{array}$ \\
\hline & Motorcycle Involved & $\begin{array}{l}\text { Implement a comprehensive helmet-wearing policy and implement policy. } \\
\text { Set up a special safety bulletin board for motorcycles to prevent speeding and overloading. } \\
\text { Strengthen the safety education and training of motorcycle drivers. }\end{array}$ \\
\hline & Intersection & $\begin{array}{l}\text { Channelize the intersection to improve the intersection. } \\
\text { Set up pedestrian crossing safety islands. }\end{array}$ \\
\hline \multirow[b]{3}{*}{ Town-center area } & Elderly driver & Strengthen safety education of elderly drivers. \\
\hline & Single-vehicle & Improve the road monitoring system and accident rescue system in the town area. \\
\hline & Nighttime & $\begin{array}{l}\text { Supplement lighting facilities. } \\
\text { Set up anti-dazzle traffic facilities. } \\
\text { Avoid using inconsistent lighting facilities to prevent drivers from being unable to adapt to } \\
\text { changes in lighting }\end{array}$ \\
\hline
\end{tabular}

\section{Conclusions}

(1) There are differences in the factors affecting the severity of accidents in the two areas. In the town-rural area, single-vehicle accidents are more likely to be serious than multi-vehicle accidents. Accidents are more likely to be serious when involved with motorcycles. Intersection accidents are prone to be more severe than non-intersection accidents. In the town-center area, older people are more likely to have serious accidents than younger people. Single-vehicle accidents are more likely to be serious. Serious accidents are more likely to occur at night than during the daytime.

(2) Town-rural areas need to improve roadside safety facilities, improve the road monitoring system, and strengthen the management of the road environment to reduce the severity of single-vehicle accidents. For motorcycle accidents, the implementation and enforcement of the helmet-wearing policy needs to be fully implemented, and in particular, strengthen the safety education and training for male motorcycle drivers. For road intersections of different grades that are prone to accidents, there should be adherence to the principles of short-term reconstruction and long-term repairs: the side branches of the road can be pruned first, the intersections can be channelized, and safety islands can be set up to reduce traffic conflicts and ensure safety.

(3) The town-center area needs to strengthen the safety management education for female drivers, improve the monitoring system and rescue system in the town center area to ensure that the casualties of bicycle accidents receive timely treatment. Supplementing or improving night lighting facilities is recommended to provide drivers with good lighting conditions.

Although this article has obtained the accident influencing factors in key areas, there are many causes of road accidents. Human behavior, especially the driving behavior of the driver, can largely determine whether an accident occurs or not. This paper extracts driver factors that are easy to quantify for analysis, such as age, gender, etc. In the future, questionnaires can be used to investigate the driver's psychological factors. Although the prediction effect of the binary logistics model is good, the model is based on the data of traffic accidents in key areas. The purpose is to obtain the factors affecting the severity of the accident. Therefore, the model is not suitable for all road and accident data. According to the characteristics of the data, the appropriate prediction model should be selected based on the study area and accident data. When necessary, the advantages of different models can be combined to carry out combined forecasting research. 
Author Contributions: Conceptualization, M.L. and H.X.; methodology, H.X.; validation, M.L., H.X. and P.S.; formal analysis, H.X.; resources, M.L.; data curation, M.L. and H.X.; writing-original draft preparation, H.X.; writing-review and editing, M.L., H.X. and P.S.; supervision, M.L. All authors have read and agreed to the published version of the manuscript.

Funding: This research received no external funding.

Institutional Review Board Statement: Not applicable.

Informed Consent Statement: Not applicable.

Data Availability Statement: Not applicable.

Conflicts of Interest: The authors declare no conflict of interest.

\section{References}

1. Wei, V.F.; Lovegrove, G. Sustainable road safety: A new (?) neighbourhood road pattern that saves VRU lives. Accid. Anal. Prev. 2012, 44, 140-148. [CrossRef] [PubMed]

2. Lozano, R.; Naghavi, M.; Foreman, K.; Lim, S.; Shibuya, K.; Aboyans, V.; Abraham, J.; Adair, T.; Aggarwal, R.; Ahn, S.Y.; et al. Global and regional mortality from 235 causes of death for 20 age groups in 1990 and 2010: A systematic analysis for the Global Burden of Disease Study 2010. Lancet 2012, 380, 2095-2128. [CrossRef]

3. Ministry of Transport of the People's Republic of China. Statistical Bulletin on the Development of the Transportation Industry in 2019. Available online: http://www.gov.cn/xinwen/2020-05/12/content_5510817.htm (accessed on 30 June 2021).

4. Ministry of Transport of the People's Republic of China. Measures for the Administration of Rural Road Construction (Order No. 4 of 2018 of the Ministry of Transport of the People's Republic of China). Available online: https://www.mot.gov.cn/ zhengcejiedu/nongcungljsglbf/xiangguanzhengce/201805/t20180508_3017921.html (accessed on 21 April 2021).

5. Xu, J.; Bai, J.; Chen, J. An Improved Indicator System for Evaluating the Progress of Sustainable Development Goals (SDGs) Sub-Target 9.1 in County Level. Sustainability 2019, 11, 4783. [CrossRef]

6. Pojani, D.; Stead, D. Sustainable Urban Transport in the Developing World: Beyond Megacities. Sustainability 2015, 7, 7784-7805. [CrossRef]

7. Chen, J.H.; Guo, F.; Wang, H.; Wang, Z.F.; Wu, Y. Urban Land Revenue and Sustainable Urbanization in China: Issues and Challenges. Sustainability 2018, 10, 2111. [CrossRef]

8. Chengwei, F.; Mingxing, C. Review on Urban-rural Linkage in China. Prog. Geogr. 2010, 29, 1525-1531. [CrossRef]

9. Youqi, C. Discussion on the name of urban and rural ecotone. Geogr. Geogr. Inf. Sci. 1995, 11, 47-52.

10. Di, W. Research on Traffic Safety and Improvement Methods at the Intersection of Urban and Rural Areas. Master's Thesis, Chongqing Jiaotong University, Chongqing, China, 2018.

11. Zhao, P.; Wan, J. Land use and travel burden of residents in urban fringe and rural areas: An evaluation of urban-rural integration initiatives in Beijing. Land Use Policy 2021, 103, 105309. [CrossRef]

12. Khorashadi, A.; Niemeier, D.; Shankar, V.; Mannering, F. Differences in rural and urban driver-injury severities in accidents involving large-trucks: An exploratory analysis. Accid. Anal. Prev. 2005, 37, 910-921. [CrossRef] [PubMed]

13. Wang, Z.; Yue, Y.; Li, Q.; Nie, K.; Tu, W.; Liang, S. Analyzing Risk Factors for Fatality in Urban Traffic Crashes: A Case Study of Wuhan, China. Sustainability 2017, 9, 897. [CrossRef]

14. Islam, S.; Brown, J. A comparative injury severity analysis of motorcycle at-fault crashes on rural and urban roadways in Alabama. Accid. Anal. Prev. 2017, 108, 163-171. [CrossRef] [PubMed]

15. Wu, Q.; Zhang, G.; Zhu, X.; Liu, X.C.; Tarefder, R. Analysis of driver injury severity in single-vehicle crashes on rural and urban roadways. Accid. Anal. Prev. 2016, 94, 35-45. [CrossRef] [PubMed]

16. Rahimi, E.; Shamshiripour, A.; Samimi, A.; Mohammadian, A. Investigating the injury severity of single-vehicle truck crashes in a developing country. Accid. Anal. Prev. 2020, 137, 105444. [CrossRef] [PubMed]

17. Nguyen-Phuoc, D.Q.; De Gruyter, C.; Oviedo-Trespalacios, O.; Diep Ngoc, S.; Tran, A.T.P. Turn signal use among motorcyclists and car drivers: The role of environmental characteristics, perceived risk, beliefs and lifestyle behaviours. Accid. Anal. Prev. 2020, 144, 105611. [CrossRef]

18. Pokorny, P.; Jensen, J.K.; Gross, F.; Pitera, K. Safety effects of traffic lane and shoulder widths on two-lane undivided rural roads: A matched case-control study from Norway. Accid. Anal. Prev. 2020, 144, 105614. [CrossRef]

19. Watson, C.E.; Austin, R.A. Differences in rural and urban drivers' attitudes and beliefs about seat belts. Accid. Anal. Prev. 2021, 151, 105976. [CrossRef] [PubMed]

20. Kmet, L.; Macarthur, C. Urban-rural differences in motor vehicle crash fatality and hospitalization rates among children and youth. Accid. Anal. Prev. 2006, 38, 122-127. [CrossRef]

21. Singh, H.; Kathuria, A. Analyzing driver behavior under naturalistic driving conditions: A review. Accid. Anal. Prev. 2021, 150, 105908. [CrossRef]

22. Colonna, P.; Berloco, N.; Intini, P.; Ranieri, V. Geometric Design Issues and Safety Analysis of Two-way Rural Road Tunnels. Transp. Res. Procedia 2020, 45, 38-45. [CrossRef] 
23. Calvo-Poyo, F.; de Oña, J.; Garach Morcillo, L.; Navarro-Moreno, J. Influence of Wider Longitudinal Road Markings on Vehicle Speeds in Two-Lane Rural Highways. Sustainability 2020, 12, 8305. [CrossRef]

24. Shah, S.A.R.; Ahmad, N.; Shen, Y.; Pirdavani, A.; Basheer, M.A.; Brijs, T. Road Safety Risk Assessment: An Analysis of Transport Policy and Management for Low-, Middle-, and High-Income Asian Countries. Sustainability 2018, 10, 389. [CrossRef]

25. Albalate, D.; Fageda, X. Congestion, Road Safety, and the Effectiveness of Public Policies in Urban Areas. Sustainability 2019, 11, 5092. [CrossRef]

26. Balakrishnan, S.; Karuppanagounder, K. Cost of two-wheeler road accidents in India. Int. J. Inj. Control Saf. Promot. 2019, 26, 185-191. [CrossRef] [PubMed]

27. Kaygisiz, Ö.; Senbil, M.; Yildiz, A. Influence of urban built environment on traffic accidents: The case of Eskisehir (Turkey). Case Stud. Transp. Policy 2017, 5, 306-313. [CrossRef]

28. Eluru, N. Evaluating alternate discrete choice frameworks for modeling ordinal discrete variables. Accid. Anal. Prev. 2013, 55, 1-11. [CrossRef]

29. Feizi, A.; Oh, J.-S.; Kwigizile, V.; Joo, S. Cycling environment analysis by bicyclists' skill levels using instrumented probe bicycle (IPB). Int. J. Sustain. Transp. 2020, 14, 722-732. [CrossRef]

30. Jalayer, M.; Shabanpour, R.; Pour-Rouholamin, M.; Golshani, N.; Zhou, H. Wrong-way driving crashes: A random-parameters ordered probit analysis of injury severity. Accid. Anal. Prev. 2018, 117, 128-135. [CrossRef]

31. Quddus, M.A.; Wang, C.; Ison, S.G. Road Traffic Congestion and Crash Severity: Econometric Analysis Using Ordered Response Models. J. Transp. Eng. 2010, 136, 424-435. [CrossRef]

32. Arvin, R.; Kamrani, M.; Khattak, A.J. The role of pre-crash driving instability in contributing to crash intensity using naturalistic driving data. Accid. Anal. Prev. 2019, 132, 105226. [CrossRef] [PubMed]

33. Cerwick, D.M.; Gkritza, K.; Shaheed, M.S.; Hans, Z. A comparison of the mixed logit and latent class methods for crash severity analysis. Anal. Methods Accid. Res. 2014, 3, 11-27. [CrossRef]

34. Hong, J.; Tamakloe, R.; Park, D. A Comprehensive Analysis of Multi-Vehicle Crashes on Expressways: A Double Hurdle Approach. Sustainability 2019, 11, 2782. [CrossRef]

35. Soares, S.; Campos, C.; Leitão, J.M.; Lobo, A.; Couto, A.; Ferreira, S. Distractive Tasks and the Influence of Driver Attributes. Sustainability 2021, 13, 5094. [CrossRef]

36. Witchayaphong, P.; Pravinvongvuth, S.; Kanitpong, K.; Sano, K.; Horpibulsuk, S. Influential Factors Affecting Travelers' Mode Choice Behavior on Mass Transit in Bangkok, Thailand. Sustainability 2020, 12, 9522. [CrossRef]

37. Liu, X.; Gao, L.; Ni, A.; Ye, N. Understanding Better the Influential Factors of Commuters' Multi-Day Travel Behavior: Evidence from Shanghai, China. Sustainability 2020, 12, 376. [CrossRef]

38. National Bureau of Statistics. Provisions for the Statistical Division of Urban and Rural Areas. Available online: http://www. stats.gov.cn/tjsj/tjbz/200610/t20061018_8666.html (accessed on 21 April 2021).

39. National Bureau of Statistics. Compilation Rules for Statistical Zoning Codes and Urban-Rural Zoning Codes. Available online: http:/ / www.stats.gov.cn/tjsj/tjbz/200911/t20091125_8667.html (accessed on 21 April 2021).

40. Transportation Bureau. Provisions on the Procedures for Handling Road Traffic Accidents (Order No. 146 of the Ministry of Public Security). Available online: https:/ /app.mps.gov.cn/gdnps/pc/content.jsp?id=7449662 (accessed on 21 April 2021).

41. Cameron, M. World report on road traffic injury prevention. Inj. Prev. 2004, 10, 255-256.

42. Cohen, J. Statistical Power Analysis for the Behavioral Sciences; L. Erlbaum Associates: Hillsdale, NJ, USA, 1988.

43. Fisher, R.A. On the Interpretation of $\chi 2$ from Contingency Tables, and the Calculation of P. J. R. Stat. Soc. 1922, 85, 87-94.

44. Hosmer, D.W.; Hosmer, T.; Le Cessie, S.; Lemeshow, S. A comparison of goodness-of-fit tests for the logistic regression model. Stat. Med. 1997, 16, 965-980. [CrossRef]

45. Wentong, Z.; Wei, D. SPSS Statistical Analysis Advanced Tutorial, 2nd ed.; Higher Education Press: Beijing, China, 2013.

46. Johnston, J. Econometric Methods, 3rd ed.; McGraw-Hill Book Company: New York, NY, USA, 1984.

47. Lusted, L.B. ROC Recollected. Med. Decis. Mak. 1984, 4, 131-135. [CrossRef]

48. Lusted, L.B. Logical analysis in roentgen diagnosis. Radiology 1960, 74, 178-193. [CrossRef]

49. Fawcett, T. An introduction to ROC analysis. Pattern Recognit. Lett. 2006, 27, 861-874. [CrossRef]

50. Kim, C.-Y.; Wiznia, D.H.; Averbukh, L.; Dai, F.; Leslie, M.P. The Economic Impact of Helmet Use on Motorcycle Accidents: A Systematic Review and Meta-analysis of the Literature from the Past 20 Years. Traffic Inj. Prev. 2015, 16, 732-738. [CrossRef]

51. Ahlstrom, C.; Victor, T.; Wege, C.; Steinmetz, E. Processing of Eye/Head-Tracking Data in Large-Scale Naturalistic Driving Data Sets. IEEE Trans. Intell. Transp. Syst. 2012, 13, 553-564. [CrossRef]

52. Feng, F.; Bao, S.; Sayer, J.R.; Flannagan, C.; Manser, M.; Wunderlich, R. Can vehicle longitudinal jerk be used to identify aggressive drivers? An examination using naturalistic driving data. Accid. Anal. Prev. 2017, 104, 125-136. [CrossRef] 